\title{
The effectiveness of food handler training programmes in Malaysia and Ireland to prevent food-borne disease
}

\author{
${ }^{1}$ *Tirmizi, L.I.T., ${ }^{2,3}$ Son, R., ${ }^{2}$ New, C.Y. and ${ }^{1}$ Brand, H. \\ ${ }^{1}$ Faculty of Health, Medicine and Life Sciences, Universiteitssingel 40, 6229 Maastricht, The Netherlands \\ ${ }^{2}$ Department of Food Science, Faculty of Food Science and Technology, Universiti Putra Malaysia, 43400 \\ UPM Serdang, Selangor Darul Ehsan, Malaysia \\ ${ }^{3}$ Food Safety and Food Integrity, Institute of Tropical Agriculture, Universiti Putra Malaysia, 43400 UPM \\ Serdang, Selangor Darul Ehsan, Malaysia
}

\begin{abstract}
Article history:
Received: 30 November 2017

Received in revised form: 2

January 2018

Accepted: 6 January 2018

Available Online: 17 January 2018
\end{abstract}

\section{Keywords:}

Food handlers training programmes,

Food safety knowledge,

Food safety practices,

Food-borne disease,

Systematic literature review,

Narrative literature review

\section{DOI:}

https://doi.org/10.26656/fr.2017.2(3).015

\section{Abstract}

According to the World Health Organisation (WHO), globally 600 million people suffer from food-borne diseases (FBD), and 420,000 people die as a result. The European Food Safety Authority (EFSA) has stated that FBD are linked to the food industry, with the most common means of transmission being due to poor food handling and hygiene by food handlers working in the food industry. The aim of this research was to investigate the effectiveness of mandatory food handler training programmes (FHTP) to prevent FBD in Malaysia and Ireland. To do this, the FHTP existing in Malaysia and Ireland were analysed, in addition to the legislation they fall under in each respective country. Effectiveness was determined by investigating the level of food safety knowledge (FSK) and food safety practices (FSP) of food handlers in Malaysia and Ireland. A systematic literature review (SLR) and a narrative literature review (NLR) were conducted for this research. The SLR was based on the PRISMA diagram, using the Confidence in the Evidence from Reviews of Qualitative research (CERQual) approach to evaluate the studies used for this research. A total of 8 Malaysian studies and 1 Irish study were used to determine the level of FSK and FSP of food handlers in each respective country, to examine the effectiveness of FHTP. The results of the studies used for this research have depicted overall good FSP and FSK of food handlers in Malaysia and Ireland; yet trends continue to show that food handlers are one of the biggest contributors to FBD, demonstrating that FHTP are not effective in preventing FBD. The findings from this research highlights that although these trainings can be an effective tool to prevent FBD, if they are not executed correctly, food handlers will continue to contribute to FBD.

\section{Introduction}

According to the WHO (2017) FBD are defined as illnesses caused by the consumption of foodstuff that have been contaminated by microorganisms or chemicals. The 'WHO Estimates of the Global Burden of Food-borne Diseases' report states that 600 million or almost 1 in 10 people suffer from FBD globally, and 420, 000 people die annually as a result. Additionally, one third of FBD infect children under the age of 5, even though they make up only $9 \%$ of the world's population. This makes children under the age of 5 years old the most vulnerable population group to FBD worldwide. These numbers make the burden of FBD a global public health concern (WHO, 2015).

According to the WHO's report (2015), Africa has the highest foodborne illness burden per population followed by South-East Asia and Eastern Mediterranean. However, in the report, Malaysia was not placed under the South-East Asia subregion, but placed under the West Pacific Region. Still, this does not indicate that the foodborne illness in Malaysia is low. According to the Malaysian Ministry of Health $(\mathrm{MMoH})$ incidence case reports compiled in New et al. (2017), foodborne poisoning cases were seemingly fluctuated from 2005 to 2015. The recent report in 2015 recorded an incidence rate of 47.34 per 30.3 million population size.

From a European perspective the WHO European region, of which Ireland belongs to, has the lowest FBD burden and mortality rate in comparison to all other WHO regions. More than 23 million people contract a FBD annually, with 5,000 of these cases resulting in 
death (WHO, 2015). Considering this region has a population size of 739 million (Worldometers, 2017a) these numbers are significantly low. In 2000, thirty-six outbreaks of infectious intestinal disease were reported to the Food Safety Authority Ireland (FSAI) (National Disease Surveillance Centre, 2004) while in the following year, that figure dropped to twenty-seven. However, in 2007, that figure rose greatly to 238 (Health Protection Surveillance Centre, 2007). Despite this considerable increase, these figures are still low as Ireland has a population size of approximately 4.7 million (Worldometers, 2017b).

According to the WHO and Food Agriculture Organisation (FAO) (2002), annually the consumption of unsafe food accounts for millions of illnesses, and in many cases deaths. These illnesses and deaths are linked to the food industry and the services provided by food companies (EFSA, 2010). One of the most common ways in which FBD and cross-contamination spreads in the food industry is poor food handling and hygiene by the food service providers, in particular food handlers (Sani and Siow, 2014). The WHO defines a food handler as "any person who directly handlers packaged or unpacked food, food equipment and utensils, or food contact surfaces" (WHO, 2006). According to Bryan (1988), food handlers who fail to participate in proper food handling practices contribute to outbreaks of FBD in the food industry. In addition, EFSA and the European Centre for Disease Prevention (ECDC) (2015), stated that food handlers are deemed one of the two most common contributory factors to FBD. Evidence from EFSA and ECDC's scientific report shows that food handlers infected with FBD pathogens were accountable for $7.3 \%$ of reported FBD outbreaks, food handler mistakes with regards storage temperatures contributed to $3.9 \%$ of reported FBD outbreaks, and crosscontamination as a result of improper food handler practices contributed to $3.2 \%$ of reported FBD outbreaks in 2014 (EFSA and ECDC, 2015). Furthermore, it was determined by the Scientific Opinion of EFSA's Panel on Biological Hazards that food handler interaction with poultry and meat contributed to $20-30 \%$ of Campylobacter (one of the leading FBD in the EU) outbreaks in 2013 (EFSA Panels on Biological Hazards on Contaminants, and on Animal Health and Welfare, 2012).

One of the key factors identified to this issue is the food handling training programs (FHTP) conducted. The outbreak cases caused by food handlers puts a paucity on the effectiveness of FHTP. Theoretically, the spread of FBD by food handlers can be prevented with good food safety knowledge and practice through effective FHTP. Thus, this research is aimed to determine the effectiveness of FHTP in disseminating the FSK and FSP among food handlers in Malaysia and Ireland. The research will investigate the FSK and FSP of Malaysian and Irish food handlers respectively and, by using this information, the effectiveness of the FHTP implemented of the respective countries will be measured.

\section{Methodology}

The methodology of this research was conducted with the use of both a NLR and a SLR, which was based on the PRISMA diagram (Moher et al., 2009) depicted in Figure 1. This illustrates the process of a SLR in terms of identifying studies, screening the studies, determining the eligible studies and defining which studies would be included for this research.

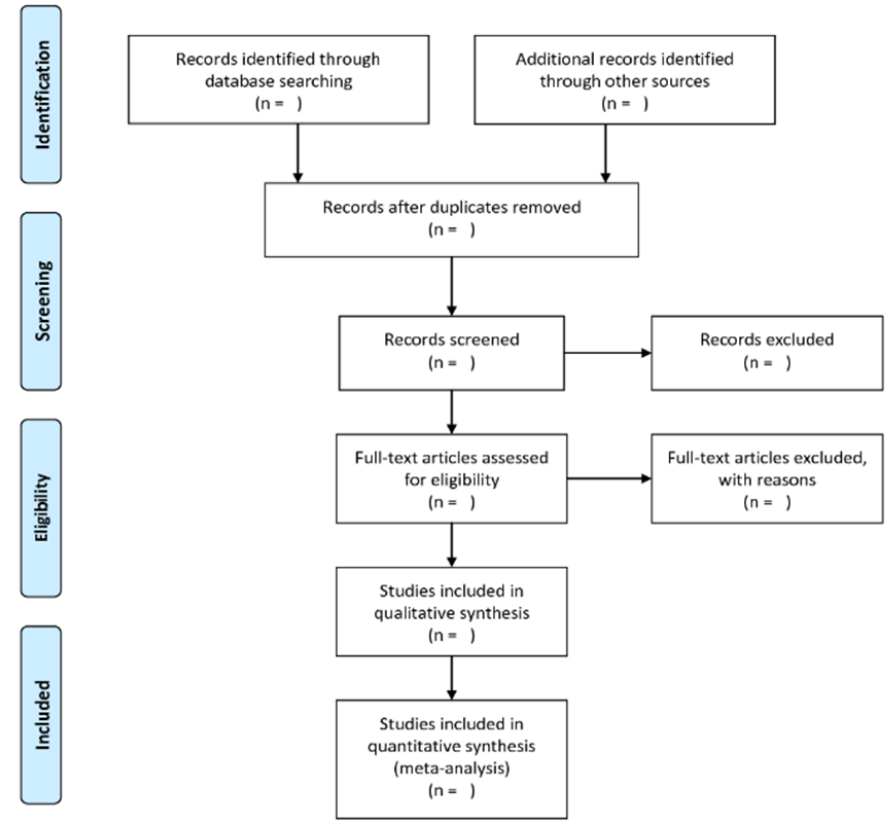

Figure 1. PRISMA 2009 Flow Diagram of Component Studies

\subsection{Criteria for literature search}

In order to collect an extensive amount of relevant literature and publications, inclusion and exclusion criteria were selected based on language, date of publication and types of publication. The inclusion and exclusion criteria differed for the NLR and the SLR.

The language of the publications that are to be included are restricted to English only. The reason for this is because this is the only language the researcher is knowledgeable in. All other languages were excluded. This was applied to both NLR and SLR.

For NLR, the restriction on the date of publication ranges from the year 1987-2017, providing a range of 30 years. The reason for this is because the information regarding the food safety implementation in Malaysia and Ireland should be gathered as much as possible into 
the food safety measures in each respective country. Additionally, the cut-off point at 30 years allows for a larger scope of the situation of FBD and how it has changed over the years. As for SLR, the restriction on the date of publication ranges from the year 2004-2017, providing a range of 13 years. The justification for this is because studies required for this research are needed from the dates of implementations of the two pieces of legislation that this research is based on: the Food Hygiene Regulations 2009 and the EC/852/2004. As the Food Hygiene Regulations 2009 was implemented in 2009 , and the EC/852/2004 was implemented in 2004, it was appropriate to choose the older piece of legislation as the cut-off point for the date of publication. Therefore, any publications published before 2004 were excluded.

The types of publications included are journals, books, articles and information from institutional websites such as the European Commission, the WHO, the Food Safety and Quality Division and others for NLR. While for SLR, the types of publications include studies found in scientific journals, books or articles. Both experimental and observation studies are included. In addition, there is no restriction on qualitative or quantitative results received from the study designs, and therefore no exclusion criteria regarding this.

Targeted participants for this research are selected based on the following criteria: 1 . Food handlers and; 2 . Reside in Malaysia or Ireland.

\subsection{Data collection}

\subsubsection{Resources}

Scientific databases available online were used when conducting the NLR and the SLR. These included PubMed, Science Direct and Google Scholar. In addition, university libraries including the Maastricht University Online Library and the Universiti Putra Malaysia Online Library were accessed to provide a wider search. Although it was possible to restrict the literature search in terms of language and date of publication on the mentioned databases, but it was not enough. In order to refine the literature search even further, the use of predetermined Medical Subject Headings (MesSH) terms and the Boolean operators were essential. In addition, the snowball technique was employed to widen the search using publications that had already been acquired.

In addition, this research required a lot of information regarding legal mandates and legal frameworks. Therefore, the websites of governmental institutions such as the $\mathrm{MMoH}$, the Food Safety Quality Division, the European Commission, the European Food and Safety Authority and the Food Safety Authority
Ireland were used.

\subsubsection{Selection}

Each publication and piece of literature used for this research was selected by the researcher based on the inclusion/exclusion criteria.

\subsubsection{Quality assessment and risk of bias}

The quality and risk of bias of the studies found using the SLR were assessed using the CERQual approach. CERQual evaluates the quality of studies and risk of bias with the use of four components as follows: 1. Methodological limitations of the primary studies; 2 . Relevance of the primary studies to the literature review research question; 3 . Coherence of the literature review with the primary studies; and 4. Adequacy of data to support the literature review findings.

Once these components were assessed, the level of confidence was determined. These were divided into high, moderate, low and very low: high confidence implied that the literature review was most likely a reasonable representation of the phenomenon of interest; moderate confidence signified that the literature review is a reasonable representation of the phenomenon of interest; low confidence indicated that the literature review is a possible reasonable representation of the phenomenon of interest; and very low confidence means that it is unclear whether or not the literature review is a reasonable representation of the phenomenon of interest.

\section{Results}

The results for this research is divided into sections which build upon each other to form a structured and coherent answer to the research question. The first section provides a brief description of the Food Hygiene Regulations 2009, pertaining to food handlers specifically that exists in Malaysia. The second section gives a detailed description of the mandatory FHTP in Malaysia, known as Sekolah Latihan Pengendali Makanan (SLPM), including its objective and the training and education that is involved in these programmes. The third section provides an account of the Malaysian studies used to determine the FSK and FSP of food handler in Malaysia. The fourth section is the European perspective, providing information about the EC/852/2004 policy. The fifth section details the Irish FHTP on food safety namely the Train the Trainers Workshop (TTW) and the Food Safety and You Induction Porgram (FSY-IP) that fall under the EU $\mathrm{EC} / 852 / 2004$. The sixth section provides an account of the Irish study used to determine the FSK and FSP of food handlers in Ireland. Lastly, the Irish intervention 
known as Safefood (Safefood, n.a.) which promotes food safety at a school-based level, was examined in the seventh section.

\subsection{Food Hygiene Regulations 2009}

The Food Hygiene Regulations 2009 contains provisions to ensure a high level of sanitary and hygiene in the food industry, particularly among food handlers and on the food premise (Ismail, 2011). A food premise in this context was defined as "premises used for or in connection with the preparation, preservation, packaging, storage, conveyance, distribution or sale of any food, or the relabelling, reprocessing or reconditioning of any food" (Food Act 1983, 2012). The Food Hygiene Regulations 2009 is divided into seven parts. These are Part 1: Preliminary, Part 2: Registration of food premises, Part 3: Conduct and maintenance of food premises, Part 4: Food Handler, Part 5: Special requirement in handling, preparing, packing, serving, storing and selling specific food, Part 6: Carriage of food and Part 7: Miscellaneous (Food Hygiene Regulations 2009, 2009). Parts 3 and 4 were identified as the most relevant parts for this research as they contained the regulations regarding Sekolah Latihan Pengendali Makanan (SLPM).

In Part 3: Conduct and maintenance of food premises, it was divided into three chapters. However, the most significant regulation with regards this research falls under Chapter 1: Duty of proprietor, owner or occupier of food premises. Regulation 9: food safety assurance programme stated that:

"(1) A proprietor, owner or occupier of food premises specified in the Third Schedule shall provide and make available a food safety assurance programme in the food premises.

(2) Any proprietor, owner or occupier of food premises who fails to comply with subregulation (1) commits an offence and shall, on conviction, be liable to a fine not exceeding ten thousand ringgit or to imprisonment for a term not exceeding two years." (Food Hygiene Regulations 2009, 2009)

According to the Food Safety and Quality Division Annual Report (2012) on Food Safety and Quality, "food safety assurance $[\ldots]$ were developed, implemented and monitored to further improve food safety $[. .$.$] in order to$ reduce food contamination and the occurrence of food poisoning". Programs and activities related to food safety assurance train and educate employees working in food premises on the importance of food safety. The $\mathrm{MMoH}$ has developed a number of food safety assurance program, one of them was SLPM (Food Safety and
Quality Division, 2012).

In Part 4: Food Handler, it was divided into two chapters and contained the requirements that food handlers must adhere to before being able to handle food, and the regulations for the protection of food. The most relevant regulation with regards to this research was listed under Chapter 1: Training, medical examination and health condition, clothing and personal hygiene of food handler, Regulation 30: food handler training, which stated:

"(1) All food handlers shall undergo a food handlers' training in, and obtain a Certificate of Food Handlers Training from, an institution specified by the Director.

(2) The Minister may, if he thinks necessary, require any food handler to attend any additional food handlers training in any institution specified by the Director.

(3) Any food handler who works in any food premises fails to undergo a training or obtain a certificate referred to in subregulation (1) or fails to attend any additional training referred to in subregulation (2) commits an offence and shall, on conviction, be liable to a fine not exceeding ten thousand ringgit or to imprisonment for a term not exceeding two years.” (Food Hygiene Regulations 2009, 2009).

\subsection{Sekolah Latihan Pengendal Makanan (SLPM)}

The objective of the SLPM is to allow food handlers to acquire the knowledge and skills required to comply with food safety measures outlined in the Malaysia Food Act 1983. These safety measures were put in place to ensure individuals are consuming safe food in Malaysia. SLPM provides many training and education centres located nationwide, each with instructors and programmes accredited by the $\mathrm{MMoH}$. The curriculum for these programmes is based on the general principles of food hygiene. This includes a basic understanding and knowledge regarding hygiene and sanitation in food handling and preparation, cleanliness regarding internal factors, cleanliness regarding external factors, correct storage temperatures and identifying consumable and inconsumable foods. Furthermore, food handlers are educated in awareness, particularly how their own actions can result in contamination. For instance, instructors highlight the importance of wearing gloves, hair covers and aprons, as well as keeping nails short and prohibiting the wearing jewellery as all of these actions can contribute largely to cross-contamination. In addition, food handlers are given the opportunity to practice the correct ways to handle and prepare food in their work premise, with an instructor present who advises and comments on what is correct or incorrect. 
The State Health Department often observes these programmes, to ensure that the SLPM is producing well educated and trained food handlers in food safety (Ishak et al., 2013).

\subsection{Malaysian FSK and FSP component studies}

A number of qualitative studies have been conducted in Malaysia to determine the level of FSK and FSP of food handlers. The studies found were conducted after the implementation of the Food Hygiene Regulations 2009 , and hence, it was assumed that the population samples in the reported studies have attended a SLPM course in accordance with this regulation.

A total of eight studies to determine FSK and FSP among Malaysian food handlers were found and used for this research as listed in Table 1. These studies have an observational study design and were conducted predominantly with the use of questionnaires, in addition to face-to-face interviews. Out of the eight studies, seven contained questions with a FSK and a FSP section, while one contained questions to determine FSK only. The results of each study were based on scoring system whereby points were given based on the answer to a question. The mean scores for FSK and FSP of each study were calculated and converted into percentages. Scores below 50\% were considered poor, and scores above $50 \%$ are considered good.

The FSK sections consisted of questions that could be answered with 'yes', 'no', 'true', 'false', 'not sure' or
'I don't know' depending on the study. For every correct answer, one point was rewarded, while for every incorrect answer, no points were rewarded. Respondents who answered with 'I don't know' or 'not sure' received zero points. The FSP sections consisted of questions or statements that were answered using a 5-scale Likerttype to measure the degree of agreement of the respondents to the questions or statements. The answers in the Likert-type scale ranged from strongly disagree strongly agree or, never - always with points on a scale of $0-4$.

\section{$3.4 E C / 852 / 2004$}

The EC/852/2004 is divided into 12 chapters as follows: Chapter 1: General requirements for food premises, Chapter 2: Specific requirements in rooms where foodstuff are prepared, treated or processed, Chapter 3: Requirements for movable and/or temporary premises, Chapter 4: Transport, Chapter 5: Equipment requirements, Chapter 6: Food Waste, Chapter 7: Water Supply, Chapter 8: Personal Hygiene, Chapter 9: Provisions applicable to foodstuff, Chapter 10: Provisions applicable to the wrapping and packaging of foodstuff, Chapter 11: Heat treatment, and Chapter 12: Training (European Commission, 2004).

Chapter 12: Training was focused in this research as the chapter contained rules regarding on the food handler training in EU. The reason this aspect was emphasized was to provide an EU perspective to the regulation of mandatory SPLM stated in the Food Hygiene

Table 1. Collection of Malaysian FSK and FSP component studies

\begin{tabular}{|c|c|c|c|c|c|c|}
\hline Study Reference & Location & $\begin{array}{l}\text { Sample } \\
\text { Size }\end{array}$ & $\begin{array}{c}\text { Mean } \\
\text { Score of } \\
\text { FSK }(\%) \\
\end{array}$ & $\begin{array}{c}\text { Mean } \\
\text { Score of } \\
\text { FSP }(\%)\end{array}$ & $\begin{array}{l}\text { Rating } \\
\text { for FSK }\end{array}$ & $\begin{array}{l}\text { Rating } \\
\text { for FSP }\end{array}$ \\
\hline Abdul Mutalib et al. (2012) & Kuala Pilah, Negeri Sembilan & 64 & 83.98 & 77.04 & Good & Good \\
\hline Sani and Siow (2014) & $\begin{array}{l}\text { Universiti Kebangsaan } \\
\text { Malaysia, Selangor }\end{array}$ & 112 & 19.68 & 90.02 & Poor & Good \\
\hline Woh et al. (2016) & Peninsula Malaysia & 383 & 31.1 & 69.8 & Poor & Good \\
\hline Rosnani et al. (2014) & $\begin{array}{c}\text { Wilayah Persekutuan } \\
\text { Putrajaya }\end{array}$ & 127 & 90.3 & 92.9 & Good & Good \\
\hline Lee et al. (2017) & $\begin{array}{l}\text { Wilayah Persekutuan Kuala } \\
\text { Lumpur }\end{array}$ & 85 & 61.7 & $53.2-60.0$ & Good & Good \\
\hline Rahman et al. (2012) & Kuching, Sarawak & 361 & 41.6 & 71.5 & Poor & Good \\
\hline Nee and Sani (2011) & $\begin{array}{c}\text { Universiti Kebangsaan } \\
\text { Malaysia, Selangor }\end{array}$ & 65 & 57.8 & 66.5 & Good & Good \\
\hline Toh and Birchenough (2000) & $\begin{array}{c}\text { Wilayah Persekutuan Kuala } \\
\text { Lumpur }\end{array}$ & 100 & 18.05 & NA & Poor & NA \\
\hline
\end{tabular}

$\mathrm{NA}=$ Not Available

Table 2. Summary of Irish FSK and FSP component study

\begin{tabular}{|c|c|c|c|c|c|c|}
\hline Study Reference & Location & $\begin{array}{c}\text { Sample } \\
\text { Size }\end{array}$ & $\begin{array}{c}\text { Mean } \\
\text { Score of } \\
\text { FSK }(\%)\end{array}$ & $\begin{array}{c}\text { Mean } \\
\text { Score of } \\
\text { FSP (\%) }\end{array}$ & $\begin{array}{l}\text { Rating } \\
\text { for FSK }\end{array}$ & $\begin{array}{l}\text { Rating } \\
\text { for FSP }\end{array}$ \\
\hline Bolton et al. (2008) & Republic of Ireland & 200 & 60 & 81.5 & Good & Good \\
\hline
\end{tabular}


Regulations 2009. The rules under the chapter stated that:

"Food business operators are to ensure:

that food handlers are supervised and instructed and/or trained in food hygiene matters commensurate with their work activity;

that those responsible for the development and maintenance of the procedure referred to in Article 5(1) of this Regulation or for the operation of relevant guides have received adequate training in the application of the HACCP principles; and

compliance with any requirements of national law concerning training programmes for persons working in certain food sectors." (European Commission, 2004).

\subsection{Irish food handler training programmes}

\subsubsection{Train the Trainer Workshop (TTW)}

As Ireland is a member state of the EU, the Ireland government must incorporate the EU legislation into its national legislation and thus, this brings to the implementation of the TTW. The TTW provides managers and supervisors in the food industry with sufficient knowledge and skills to deliver the FSY-IP to their employees. This certified workshop costs $€ 300$ to deliver a FHTP to their employees known as FSY-IP and last for a duration of 2 days, whereby managers or supervisors will engage in an interactive training covering topics of food safety, as well as delivering the FHTP to their staff members. Individuals are assessed by delivering a presentation on the second day based on the FSY-IP, to evaluate the knowledge and skills of the employees as acquired from the training (FSAI, 2017).

\subsubsection{The Food Safety and You Induction Training Programme (FSY-IP)}

The FSY-IP is a 3-hour FHTP based on the FSAI's guides to food safety categorized into three levels: Level 1 - Induction Skills; Level 2 - Additional Skills; and Level 3 - Food Safety Skills for Management. Level 1 includes information about the basic skills food handlers should perform within their first month in the workplace to provide safe and consumable food to consumers. Level 2 provides additional skills that food handlers should acquire within the first three to twelve months while in the workplace. Level 3 is aimed at supervisors and managers, and comprises of food safety skills necessary to operate an establishment in the food industry (FSAI, 2014). The aim of the training programme is to "promote[s] active learning and the application of training in the work environment" (FSAI, 2017). This is achieved with the use of interactive training that involves workbooks, videos and games.

\subsection{Irish FSK and FSP component studies}

Unlike Malaysia, very few qualitative studies have been conducted in Ireland to determine the level of FSK and FSP of food handlers. Therefore, there were much fewer studies available for this research in comparison to Malaysia. Only one study was identified that determined FSK and FSP among Irish food handlers. This study has an observational study design and was conducted with the use of face-to-face interviews. The study contained questions regarding FSK and FSP, however opposed to the Malaysian studies, these questions were combined into one section. Therefore, in order to determine FSK and FSP respectively, the questions were separated first to calculate the means scores of FSK and FSP respectively.

Both the FSK and FSP questions were multiple choice questions. Each answer was calculated to provide a percentage. The percentage of respondents answered the questions correctly and incorrectly was calculated as well. However, unlike the Malaysian studies, the mean scores of FSK and FSP were not calculated. Therefore, for the purpose of this research and to make an accurate comparison, the mean scores were calculated using the scoring system conducted in the Malaysian FSK and FSP component studies and tabulated in Table 2.

\subsection{Irish Safefood Food Safety Intervention}

As only one study was found as an Irish comparison, it is interesting to acknowledge food safety interventions that exist in Ireland to prevent FBD. The Safefood intervention implemented at pre-school, primary and secondary level in Ireland, is aimed to preventing the spread of FBD and promoting awareness about food safety (Safefood, n.a.). At pre-school and primary level, children are taught about the importance of hand washing with informative posters and a song. They learn how to wash their hands properly and to get into a habit of washing their hands before they handle food (Safefood, n.a.). At secondary level, Safefood provides a certified food safety programme in which students can sit an online food hygiene examination at the end. On completion, successful students will meet the minimum training requirement to work in the food industry (Safefood, n.a.).

\section{Discussion}

\subsection{Malaysian FSK and FSP component studies}

The results from the Malaysian studies show an overall good rating for FSP among food handlers in Malaysia. However, half of the studies presented a poor 
rating for FSK. The following examines specific aspects that could be deemed influencing factors to the poor FSK ratings of half of the studies involved in this research. These factors are the population samples, the location of the research and recall ability of the population samples

Firstly, the population samples of each study could be considered a factor that contributed to the poor FSK rating of some studies. For instance, the studies of Rahman et al. (2012) and Toh and Birchenough (2000), who both received a poor FSK rating, consisted of population samples who worked at hawker stalls or street vendors. According to Omar and Ishak (2016), those working at hawker stalls or as street vendors fall under the "typical informal sector" of the Malaysian economy, and therefore, may not be registered with the MMoH As acknowledged by Ismail et al. (2016), unregistered food handlers will not avail of mandatory SPLM to be trained and educated in food safety. It could be the case that the food handlers involved in these studies may not have had any training in FSK or FSP, and thus performed poorly in the questionnaires of the studies. In contrast to this, the two studies conducted by Abdul-Mutalib et al. (2012), and Rosnani et al. (2014) respectively, contained population samples of food handlers who worked in restaurants. Both of these studies received good FSK and FSP ratings with high mean scores in both FSK and FSP. As restaurants fall in the formal sector of the Malaysian economy, these food handlers were assumed to have most likely been registered with the MMoH. Therefore, it can be assumed that their access to SPLM allowed the food handlers to gain knowledge and training in food safety and thus, they were able to receive high mean scores for FSK and FSP, providing them with a good rating in both.

Secondly, the location of the studies may be an influencing factor to poor FSK ratings. In terms of setting, the majority of the studies took place in Peninsular Malaysia. There was only one study, conducted by Rahman et al. (2012) that was located in Kuching, Sarawak, East Malaysia. As acknowledged by Naidu, "there are wide disparities between the levels of development of the different parts of the country" (Naidu, 2008). Therefore, Rahman et al. (2012) conducted their study in a much more under developed part of Malaysia, in comparison to the other studies. This factor may have contributed to the poor FSK rating score received in this study, as the East side of Malaysia may not have access to the resources the West side may have. Thus, location may be a contributing factor to the level of FSK and FSP food handlers in Malaysia have.

Lastly, the fact that poor FSK ratings were produced, while all of the studies provided good FSP ratings questions whether or not it is easier to simply forget FSK and not FSP. It may be the case that food handlers remember what to do in practice, however in terms of being knowledgeable and being able to remember material they had been taught theoretically at SPLM, they are unable to recall such information. This perhaps is an explanation as to why the two studies conducted by Nee and Sani (2011) and Sani and Siow (2014) respectively, which both took place at the University Kebangsaan Malaysia, Selangor, using canteen food handlers as their sample populations, had different FSK ratings (Table 1). In 2011, the study provided results that gave a FSK rating of good, yet in 2014 provided results that gave a FSK rating of poor. This means that between 2011 and 2014, the FSK of canteen food handlers diminished from a mean score of 57.8 to 19.68 , which was a significant decrease. The reason for this could be that those who participated in the study in 2011 and 2014 may have had more FSK when they participated in 2011, and had simply forgotten what they had learnt by 2014 , resulting in a lower FSK mean score in 2014.

\subsection{Irish FSK and FSP component study}

Although there was only one Irish study used for this research, the results of the study were somewhat unexpected. Despite the ratings for FSK and FSP being good, the mean scores of both, in particular FSK are lower than expected. As Ireland is part of the EU, it can be assumed that it would have access to more resources than a more underdeveloped Malaysia. Therefore, it may be expected that the mean score for FSK and FSP would be higher than $60 \%$ and $81.5 \%$ respectively. In particular, FSK, which only had a mean score of $10 \%$ over to achieve a good rating, is much lower than expected (Table 2). Considering that the population sample for this study consisted of head chefs and catering managers in Ireland, who take on a role at a higher position in the food industry, it can be assumed that their level of training and qualifications should be higher than most. Nevertheless, the results showed that their FSK was not at par with some of the Malaysian population samples. A reason for this could be similar to that in Malaysia, as FSK may be easier to forget than FSP. Although these individuals were aware about the correct actions and procedures to produce safe food, in terms of FSK about food policy or legislation, they seem to be lacking. Perhaps, this was due to poor memory and a complete lack of awareness which would cause the means scores of FSK to be lower than expected. In some cases, it may be that the FHTP was held too long ago for food handlers to remember particular knowledge when asked of them, and therefore were unable to answer the FSK questions correctly. Furthermore, it may be the case that the FSP questions were more familiar and easier to 
answer for the sample populations, as they were able to recall the actions they perform on a daily basis better than knowledge they acquired at a one-time training programme.

\subsection{FSK and FSP to Prevent FBD}

According to the WHO's 'Five keys to safer food manual', FSK equals the prevention of FBD. Educating those in the food industry in FSK is an imperative action to be taken by governments to reduce and prevent FBD worldwide (WHO, 2006). As acknowledged in a study by Ismail et al. (2016), the amount of FSK a food handler has, was positively associated with the practices they perform when preparing and serving food. In essence, good FSK is needed for good FSP. A food handler can perform better in practice, once they have the correct information with regards food safety. Thus, FSK is linked to FSP and it can be assumed having good FSK will lead to having good FSP, and vice versa. Nevertheless, the result provided by the studies depict a different trend. Despite all the studies' results giving good FSP ratings, half contained results with poor FSK.

It is evident that FHTP produce food handlers with an overall good level of FSK and FSP. There have been many studies that demonstrated that training in food safety increases food handler's FSK. According to studies by Lynch et al. (2003), training and educating employees who work in the food industry, vastly increases their awareness about food safety. For instance, Clayton et al. (2002) and McElroy and Cutter (2004) have established a positive link between training programmes in food safety and increase in the level of food handler's FSP. In addition, according to Costello et al. (1997) and Finch and Daniel (2005), programmes to strengthen the training and skills of food handlers in food safety develops FSK overall. With the knowledge they gain, they are able to put it into practice which reduces the risk of FBD. Moreover, educating and training individuals in the food industry may be a more effective tool to implement food safety measures, as it provides food handlers with more knowledge on how to prevent FBD, and consequently improved FSP (Gillespie et al., 2000). However, unless executed correctly, FHTP are not always effective (Adesokan et al., 2015).

\subsection{Recommendations to improve FHTP}

It was noted by Ismail et al. (2016) that some food handlers, who have good FSK do not put it into practice. Additionally, Abdul-Mutalib et al. (2012) acknowledged that despite FHTP, it was evident that many food handlers ignore or simply forget basic FSK or measures that should be employed in practice. This is demonstrated in this research as FSK was considered poor in half of the studies. Therefore, SPLM should be restructured to allow food handlers to learn what they need to know with regards FSK and FSP, and not to over stimulate their minds to the point where they are learning unnecessary information and forget or ignore the basic food safety principles. In essence, SPLM should be provided to train food handler to their optimal capacity in the most efficient way possible.

According to Adesokan et al. (2015), the most effective FHTP should last a duration of two weeks at the most. This is because food handlers become more despondent with programmes that exceed two weeks due to the repetitive nature of the knowledge and training. According to Yang (2010), who conducted a study in which food handlers partook in a food hygiene training programme which exceeded two weeks, the food handlers were noted to be dissatisfied and reported that they believed a shorter programme would have been more beneficial and interesting. Therefore, a way in which the MMoH could combat the issues whereby food handlers forget or ignore information learnt at SPLM, would be to create a standard duration period for SPLM of two weeks only. Furthermore, another effective strategy to keep food handlers informed and updated with good FSK and FSP would be with the use of regular refresher programmes. It was noted that many food handlers forget what they have learnt over time, and therefore a short duration refresher programme would allow food handlers to exercise their knowledge and keep up to date with current procedures (Adesokan et al., 2015). According to Worsfold et al. (2004), refresher programmes that allow individuals to re-train what they have learnt and update their skills increases the likelihood that the knowledge and practices will be maintained in the future.

In Malaysia, it was noted that food handler training may not reach unregistered food handlers, such as those working at hawker stalls or food vendors. This may also be the case for Irish food handlers, who work at market stalls. In order to tackle this issue, the $\mathrm{MMoH}$ should develop a new strategy to ensure that these food handlers receive some sort of training in good FSK and proper FSP. Those employed at hawker stalls or food vendors in Malaysia already have a "small[er] likelihood of being subjected to regulations" (Toh, 2000). Not only are these individuals evading certain regulations with regards food safety, but there is an issue of a lack of enforcement for these particular food handlers in Malaysia (Toh, 2000). Although a business licence is required in Malaysia to open a hawker stall, there is a "lack of concern on health issues by the relevant authorities and a lack of training of the enforcers" (Toh, 2000). This coupled with an absence of consistency in terms of licenses for food hawkers, 
particularly with regards health certificates, means it is very possible for individuals employed at hawker stalls to evade regulations (Toh, 2000). The WHO have acknowledged that FHTP for these food handlers is imperative to increase quality and safety of food sold at hawker stalls or at street vendors (WHO-International Food Safety Authorities Network, 2010), and that educating food handlers working at hawker stalls would reduce the spread of FBD (Parson, 1997). Toh (2000) suggested that the best way to tackle the issue of poorly educated food handlers in the areas of FSK and FSP working at hawker stalls in Malaysia, would be with an integrated approach. It is necessary to involve "local authorities, top foodservice management and the local police" (Toh, 2000) and those at a municipality level. With these bodies involved, it is possible to provide some sort of training for these food handlers to overall produce safe-to-consume food and reduce FBD. It has also been suggested that food safety education be integrated into the school curriculum in order to educate people from a young age on FSK. Thus, those who may become food handlers in the future will already have FSK and awareness about FSP (Toh, 2000).

Additionally, as pointed out by Toh (2000), it is important to educate individuals from a young age about food safety. Implementing food safety education at primary school or secondary school level will allow consumers to be well versed in FSK, and thus more aware of the dangers to their health of consuming contaminated food. This has already been implemented in Ireland with the Safefood intervention, which allows individuals to learn the importance of food safety from a young age. As acknowledged by Gillespie et al. (2000), educating and training individuals in the food industry may be a more effective tool to implement food safety measures, opposed to prescriptive regulations at governmental level. Therefore, the $\mathrm{MMoH}$ could learn from Ireland in this area, and should focus more on educating its citizens about the importance of food safety, to allow individuals to be aware of good FSK and FSP as both a consumer and as a food handler.

\section{Conclusion}

After conducting this research, it is evident that the findings were unexpected. Although the level of FSK and FSP of food handlers may determine the effectiveness of FHTP, this research has highlighted other influencing factors. As previously mentioned these factors include the failure of food handlers to put the knowledge they have into practice and their lack of memory about FSK; the duration of the FHTP ; the lack of refresher programmes; and the overall organisation of the training programme. In order to gain a deeper insight into the effectiveness of FHTP to prevent FBD, it would be important to analyse these influencing factors. By doing so, it would be possible to further understand the relationship between FHTP and the prevention of FBD. Understanding this link, would highlight the key areas of where these programmes need to be improved upon in order to subsequently tackle the issues of FBD caused by food handlers. The research showed that FHTP that increases the level of FSK and FSP of food handlers could prevent FBD, however only if the FHTP are executed correctly. This would require better organisation of FHTP that involves supervisors, managers, law enforcers and those at municipality level in order to ensure that food handler adhere to the correct food safety procedures they are taught. Additionally, FHTP need to be both effective and efficient to provide food handlers with the correct amount of information that they are able to retain and put into practice. Lastly, food handlers should be re-trained and re-examined to keep updated with new food safety procedures and to ensure that they are still performing at a high level. Without these changes, FHTP will continue to be an ineffective measure to prevent FBD, and amount of FBD caused by food handlers will remain the same or continue to increase.

\section{Conflicts of Interest}

The authors declare no conflicts of interest

\section{Acknowledgements}

This research is funded by Maastricht University. Special thanks to Prof. Dr. Angela Brand, Prof. Dr. Helmut Brand and Prof. Dr. Son Radu, for their continuous support and encouragement throughout this research. Not forgetting Dr. Nur Indah Ahmad, who provided the information and opportunity for research and placement at Universiti Putra Malaysia.

\section{References}

Abdul-Mutalib, N., Abdul-Rashid, M., Mustafa, S., Amin-Nordin, S., Hamat, A.H. and Osman, M. (2012). Knowledge, attitude and practices regarding food hygiene and sanitation of food handlers in Kuala Pilah, Malaysia. Food Control, 27, 289-293. https://doi.org/10.1016/j.foodcont.2012.04.001

Adesokan, H.K., Akinseye, V.O. and Adesokan, A. (2015) Food Safety Training is Associated with Improved Knowledge and Behaviours among Foodservice Establishments' Workers. International Journal of Food Science, 2015. http:// dx.doi.org/10.1155/2015/328761

Bolton, D.J., Meally, A., Blair, I.S. and Cowan, C. 
(2008). Food Safety knowledge of head chefs and catering managers Ireland. Food Control, 19(3), 291300. https://doi.org/10.1016/j.foodcont.2007.04.006

Clayton, D.A., Griffith, C.J., Price, P. and Peters, A.C. (2002). Food handlers' beliefs and self-reported practices. International Journal of Environmental Health Research, 12(1), 25-39. https:// doi.org/10.1080/09603120120110031

Costello, C., Gaddis, T., Tamplin, M. and Morris, W. (1997). Evaluating the effectiveness of two instructional techniques for teaching four food safety principles to quick service employees. Journal of Foodservice Systems, 10(1), 41-50.

European Commission. (2004). Regulation (EC) no $852 / 2004$ of the European Parliament and of the Council of 29 April 2004 on the Hygiene of Foodstuff.

European Food Safety Authority (EFSA) (2010). The community summary report on trends and sources of zoonoses, zoonotic agents, and food borne outbreaks in the European Union in 2008. The EFSA Journal, $8,1-313$

European Food Safety Authority (EFSA) and European Centre for Disease Prevention and Control (ECDC) (2015). The European Union summary report on trends and sources of zoonoses, zoonotic agents and food-borne outbreaks 2014. EFSA Journal 2015, 13 (12), 191

European Food Safety Authority Panels on Biological Hazards on Contaminants, and on Animal Health and Welfare. (2012). Scientific Opinion on the public health hazards to be covered by inspection of meat (poultry). EFSA Journal 2012, 10(6), 179

Finch, C. and Daniel, E. (2005). Food safety knowledge and behaviour of emergency food relief organization workers: Effects of food safety training intervention. Journal of Environmental Health, 67(9), 30-34.

Food Act 1983 [Act 281] (2012). Food Hygiene Regulations 2009. Kuala Lumpur, Malaysia: International Law Book Services.

Food Agriculture Organisation (FAO) and World Health Organisation (WHO). (2002). Global forum of food safety regulators. Marrakesh: World Health Organisation.

Food Hygiene Regulations 2009. (2009). Food Hygiene Regulations 2009. Kuala Lumpur, Malaysia: International Law Book Services.

Food Safety and Quality Division, Ministry of Health, Malaysia (2012). Food Safety and Quality Division Annual Report 2012. Retrieved from Ministry of Health Malaysia website: http://fsq.moh.gov.my/v5/ images/filepicker users/5ec35272cb-78/Penerbitan/
laporan\%20tahunan/Laporan-Tahunan-BKKM2012_Eng.pdf

Food Safety Authority of Ireland (FSAI). (2014). Food Safety Training A legal requirement for everyone in the food industry. Dublin: Food Safety Authority of Ireland.

Food Safety Authority of Ireland (FSAI). (2017). Induction Training Programme Food Safety and You. Retrieved on July 1, 2017 from Food Safety Authority of Ireland website: https://www.fsai.ie/ food_businesses/training/food_safety_and_you.html

Gillespie, C., Little, C. and Mitchell, R. (2000). Microbiological examination of cold ready-to-eat slices meats from catering establishments in the United Kingdom. Journal of Applied Microbiology, $88, \quad 467-474 . \quad$ https://doi.org/10.1046/j.13652672.2000.00981.x

Health Protection Surveillance Centre. (2007). Epidemiology of Outbreaks in Ireland, 2007. Dublin: HSPC Report

Ishak, N.A., Mustaffa, J., Hamid, K.A., Shaari, A., Hamzah, M.H. and Talib, M.K.M. (2013). Food Handlers Understanding about Health Aspects at Eatery Premises in the State of Kedah: Pre and Post Training Programme for Food Handlers (LPM). Asian Social Science, 9(9), 74-79. https:// doi.org/10.5539/ass.v9n9p74

Ismail, F.H., Chik, C.T., Muhammad, R., Yusoff, N.M. (2016). Food Safety Knowledge and Personal Hygiene Practices amongst Mobile Food Handlers in Shah Alam, Selangor. Procedia - Social and Behavioural Sciences, 222, 290-298. https:// doi.org/10.1016/j.sbspro.2016.05.162

Ismail, R. (2011). Food and Consumer Protection: A Study on Food Legislation of Selected Countries. ASLI Working Paper, No. 017. Singapore: Asian Law Institute

Lee, H.K., Halim, H.A., Thong, K.L. and Chai, L.C. (2017). Assessment of Food Safety Knowledge, Attitude, Self-Reported Practices, and Microbiological Hand Hygiene of Food Handlers. Environmental Research and Public Health, 14(55), 1-14. https://doi.org/10.3390/ijerph14010055

Lynch, R.A., Eledge, B.L., Griffith, C.C. and Boatright, D.T.A. (2003). A comparison of food safety knowledge among restaurant managers by sources of training and experience in Oklahoma County, Oklahoma. Journal of Environmental Health, 66, 914.

Moher, D., Liberati, A., Tetzlaff, J., Altman, D.G. and The PRISMA Group. (2009). Preferred Reporting Items for systematic reviews and meta-analyses: the 
PRISMA statement. PLoS Med, 6(7), e10000097. https://doi.org/10.1371/journal.pmed.1000097

Naidu, G. (2008). Infrastructure Development in Malaysia. International Infrastructure Development in East Asia - Towards Balanced Regional Development and Integration. ERIA Research Project Report, p. 204-227. Retrieved from ERIA website:

http://www.eria.org/publications/ research_project_reports/international-infrastructuredevelopment-in-east-asia---towards-balancedregional-development-and-in.html

National Disease Surveillance Centre. (2004). Preventing Foodborne Disease: A Focus on the Infected Food Handler. Dublin: National Disease Surveillance Centre.

Nee, S.O. and Sani, N.A. (2011). Assessment of Knowledge, Attitudes and practices (KAP) among food handlers at residential colleges and canteen regarding food safety. Sains Malaysiana, 40(4), 403410.

New, C.Y., Ubong, A., Premarathne, J.M.K.J.K., Thung, T.Y., Lee, E., Chang, W.S., Loo, Y.Y., Kwan, S.Y., Tan, C.W., Kuan, C.H. and Son, R. (2017). Microbiological food safety in Malaysia from the academician's perspective. Food Research, 1(6), 183 -202. https://doi.org/10.26656/fr.2017.6.013

Omar, A.R.C. and Ishak, S. (2016). The Business Behaviours of Malaysian Food Hawkers. International Business and Management, 12(1), 2028.

Parsons, A. (1991). Street Foods and Their Related Problems. IUfoST Newsline, 38, 13-15.

Rahman, M.M., Arif, M.A., Bakar, K. and Tambi, Z. (2012). Food Safety Knowledge, Attitude and Hygiene Practices Among Street Food Vendors in Northern Kuching City, Sarawak. Borneo Science, 31, 107-116.

Rosnani, A.H., Son, R., Mohhidin, O., Toh, P.S. and Chai, L.C. (2014). Assessment of knowledge, attitude and practices concerning food safety among restaurant workers in Putrajaya, Malaysia. Food Science and Quality Management, 32, 20-27.

Safefood (n.a.). Retrieved on July 5, 2017 from Safefood website: http://www.safefood.eu/Education.aspx

Sani, N.A. and Siow, N.O. (2014). Knowledge, attitudes and practices of food handles on food safety in food service operations at the Universiti Kebangsaan Malaysia. Food Control, 37, 210-217. https:// doi.org/10.1016/j.foodcont.2013.09.036

Toh, P.S and Birchenough, A. (2000). Food safety knowledge and attitudes: culture and environment impact on hawkers in Malaysia. Food Control, 11
(6), 447-452. https://doi.org/10.1016/S0956-7135 (00)00008-6

Toh, P.S. (2000). The Evaluation and Control of Food Safety in Hawker Foods in Kuala Lumpur. Wales: Cardiff Metropolitan University, Doctorate Thesis.

Woh, P.Y., Thong, K.L., Behnke, J.M., Lewis, J.W. and Zain, S.N.M. (2016). Evaluation of basic knowledge on food safety and foodhandling practices amongst migrant food handlers in Peninsular Malaysia. Food Control, 70, 64-73. https://doi.org/10.1016/ j.foodcont.2016.05.033

World Health Organisation - International Food Safety Authorities Network. (2010). Basic steps to improve street-vended food. INFOSAN Information Note no. 3/2010 - Safety of street-vended food.

World Health Organisation. (2006). Five Keys to Safer Food Manual. Retrieved on May 2, 2017 from World Health Organisation website: http://apps.who.int/iris/ bitstream/10665/43546/1/9789241594639_eng.pdf? ua $=1$

World Health Organisation. (2017). Health Topics Foodborne diseases. Retrieved on January 15, 2017 from World Health Organisation website: http:// www.who.int/topics/foodborne_diseases/en/

Worldometers. (2017a). Europe Population. Retrieved on January 21, 2017 from Worldometers website: http:// www.worldometers.info/world-population/europepopulation/

Worldometers. (2017b). Ireland Population. Retrieved on July 1, 2017 from Worldometers website: http:// www.worldometers.info/world-population/irelandpopulation/ 